\title{
Applying the Dynamic Critical Precipitation Method for Flash Flood Early Warning
}

\author{
Aiqing Kang1, Kang Zhang², Ji Liang'*, Baolin Yan², Xiaohui Lei ${ }^{1 * *}$, Jing Guo ${ }^{3,4}$ \\ ${ }^{1}$ China Institute of Water Resources and Hydropower Research, Beijing, P. R. China \\ ${ }^{2}$ School of Hydropower and Information Engineering, Huazhong University of Science and Technology, \\ Wuhan, P. R. China \\ ${ }^{3}$ State Key Laboratory of Disaster Prevention and Reduction for Power Grid Transmission \\ and Distribution Equipment, Changsha, China \\ ${ }^{4}$ State Grid Hunan Electric Company Disaster Prevention and Reduction Center, Changsha, China
}

Received: 10 December 2017

Accepted: 23 January 2018

\begin{abstract}
The flash flood early warning method based on dynamic critical precipitation is proposed, which takes into account the percentage saturation of soil moisture content in double-excess model. A series of historical precipitation data of various gauge stations in the upper catchment of the study area at the early warning cross-section are set as the input parameters, thereby the runoff generation and concentration in the catchment are obtained in the double-excess model, and the percent saturation of soil moisture content is calculated. Based on the warning discharge in combination with the percentage saturation of soil moisture content, the discriminant relations of the critical precipitation for the time intervals, including $0.5 \mathrm{~h}, 1 \mathrm{~h}, 1.5 \mathrm{~h}, 2 \mathrm{~h}, 2.5 \mathrm{~h}$, and $3 \mathrm{~h}$, are computed respectively using the inversion method. Using the precipitation data from ground rain gauge stations for year $\mathrm{x}$ and flood hydrograph data of $x$ typical flood events for the Dayuhe River catchment, the SCE-UA algorithm is adopted to calibrate the parameters of the double-excess model, and the discriminant functions of dynamic critical precipitation for flash flood early warning with 6 time scales are validated using $\mathrm{x}$ representative historical flood hydrographs. The qualification ratio for flash flood early warning exceeds $\mathrm{x}$, which demonstrates the feasibility and applicability of the proposed method.
\end{abstract}

Keywords: critical precipitation, double-excess model, parameter calibration, flash flood early warning

\section{Introduction}

Early warning and forecasting of flash flood disasters constitute a significant component of flash flood disaster prevention and control system, which

*e-mail: larkwater1@163.com

**e-mail: 1xh@iwhr.com serves an effective means for reducing casualties and property losses. Generally, flash flood early warning techniques aim to explore the occurrence pattern of flash flooding induced by rainstorms in order to determine the critical precipitation of flash floods based on statistical analyses of precipitation and flood data. Critical precipitation refers to the minimal magnitude of rainfall when the control section of flood prevention target reaches disaster-inducing flood stage. This paper mainly focuses on the discussion of the dynamic critical 
precipitation method, namely that the percentage saturation of soil moisture content for the catchment prior to the occurrence of the flash flood is taken into account. When the soil is relatively dry (wet), there is a greater (lesser) infiltrating depth of the precipitation, which will result in a smaller (larger) surface runoff. Both the domestic and foreign researchers show that the dynamic critical precipitation method is more superior as opposed to the static critical precipitation method [1].

The early warning indicators can be classified into three categories, i.e., rainfall early warning, water stage early warning, and discharge early warning. Rainfall early warning can be implemented based on analysis of the critical precipitation for different early warning time intervals and by combining influencing factors consisting of critical precipitation, geographical location of the flood prevention and control target, the valley contour, and early warning response time. Therefore, rainfall early warning indicators are composed of two factors, including early warning time-intervals and corresponding precipitation and, finally, the critical precipitation for various early warning time intervals should be determined; the water stage early warning indicator is mainly employed to determine the critical water stage. The critical water stage refers to the disaster-inducing stage reached by the control section of the disaster prevention target when a flash flood occurs. Besides, methods including water stagedischarge relationship, flood routing, and historical flood hydrograph may be employed to analyze and calculate the critical water stage. Normally, water stage early warning indicators may be classified into two categories comprising reservoir and river channel water stage early warning indicators; the critical discharge reflected by the discharge early warning indicator refers to the critical discharge for the control section of the flood prevention target when a flash flood occurs. Generally, based on factors including characteristics of terrain and river channel cross-section, critical flood stage and critical discharge may be interconvertible [2].

At present, numerous informative and beneficial research on the methods of calculating critical precipitation have been conducted. Wang et al. [3] adopted the concept of critical water stage (discharge) and computed critical precipitation by means of the water stage/discharge inversion method. Besides, the said method has little dependence on hydrological data, which provides a practical approach for calculating critical precipitation of areas lacking in hydrological data; Liu et al. [4] adopted the distributed hydrological model, taking into account the antecedent soil moisture content, and proposed a flash flood early warning method based on dynamic critical precipitation indicators; $\mathrm{Du}$ et al. [5] employed the single-station critical precipitation method, the rainfall intensity lower envelope method, the rainfall intensity composite process method, and the frequency curve method to calculate the critical precipitation of the Nanahe River in Tiaohe catchment, respectively, and elaborated on the practicality of the rainfall intensity lower envelope method; Zhang et al. [6] conducted flood recurrence simulation based on the FloodArea model, and calibrated the parameters according to field-observed data, thereby computing the critical precipitation. Abroad, the flash flood guidance (FFG) developed by the U.S. Hydrologic Research Center National Weather Service remains the most representative method for critical precipitation calculation [7]. The proposed method takes into consideration the antecedent soil moisture in the catchment, pre-configures the flood discharge when a flash flood disaster occurs in the catchment, and then simulates the precipitation that is required to generate the flood discharge by means of the corresponding hydrological model.

\section{Materials and Methods}

\section{Principle of Dynamic Critical Precipitation Method}

In addition to total precipitation and rainfall intensity, the scale of flash floods is closely associated with the percent saturation of soil or antecedent influencing rainfall in the catchment. When formulating critical precipitation indicators for flash flood early warning and alert, antecedent influencing precipitation of medium and small catchments within the flash flood prevention and control area should be taken into consideration and the warning critical precipitation under different conditions of antecedent influencing precipitation should be presented. The idea therefore is to obtain the real-time soil moisture of the catchment based on the precipitation already occurring in the small catchment and by means of calculation and analyses using the hydrological model. Thus, the precipitation required for the peak flood discharge at the outlet cross-section of the catchment to reach pre-set value of the early warning discharge may be deduced via inversion method, which is referred to as "FFG" (flash flood guidance) value or dynamic "critical precipitation value." When the realtime or forecasted precipitation reaches the "FFG value" [8-10], a flash flood early warning or alert will then be issued.

\section{Model Structure and Parameters}

The double-excess model for runoff generation and concentration is proposed by Wang et al. [3]. Subsequent to their analyses of runoff generation and concentration characteristics in semi-arid and semi-humid areas, the double-excess model has been used in semi-humid areas [11-15]. Besides, the runoff generation theory of this model is proposed based on a third generation method rather than saturation-excess runoff and infiltrationexcess runoff [16]. Namely, in semi-arid and semihumid areas, the total runoff contributed during the rainfall consists mainly of three components, including 


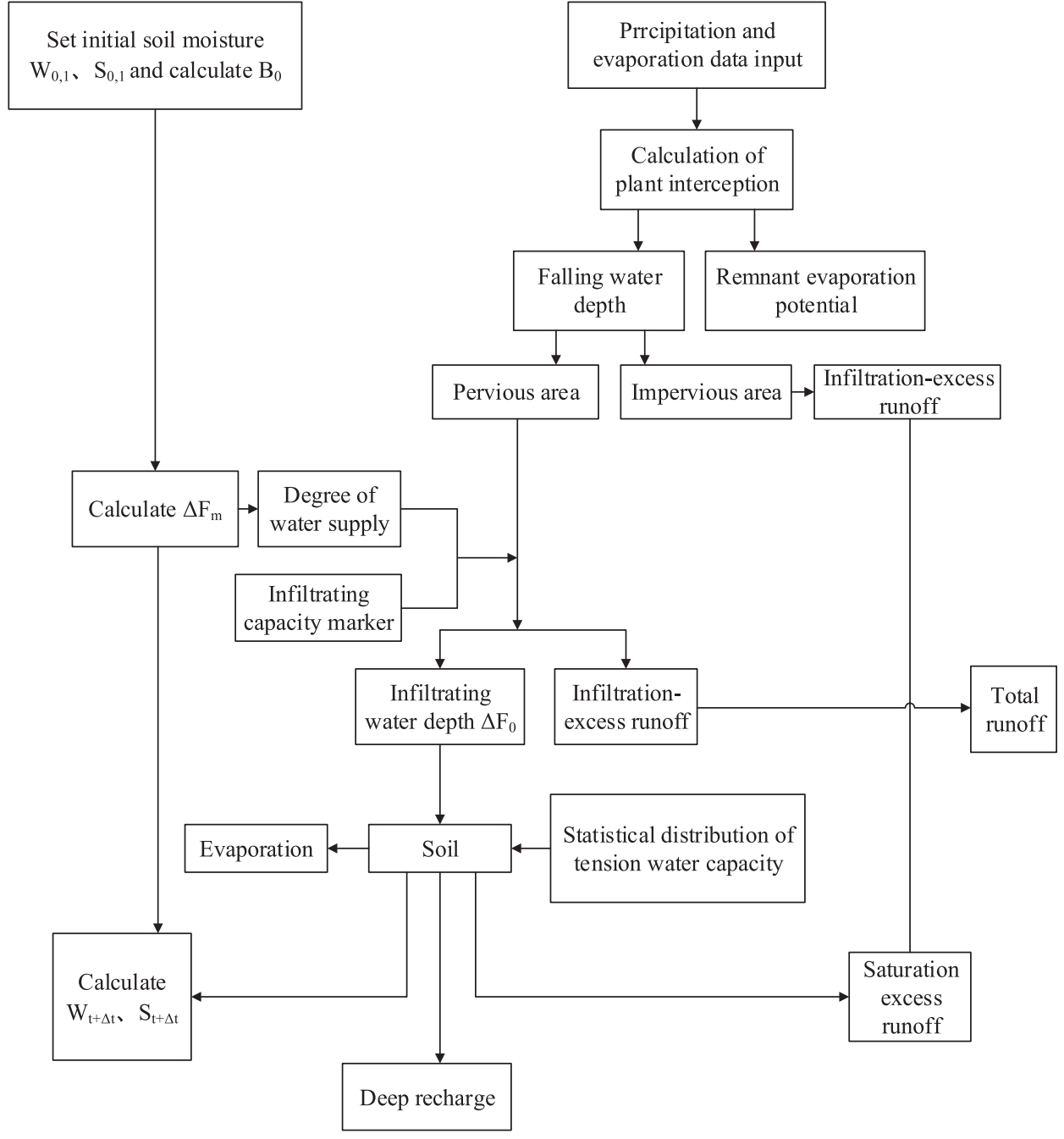

Fig. 1. Schematic runoff generation in double-excess model.

surface runoff, interflow, and groundwater runoff with a varying weight for each component.

According to forms and characteristics of runoff generation in semi-arid and semi-humid areas, the structure of double-excess model is designed based on the physical mechanism that underlies three types of water sources. It comprises the following 5 major components, namely the pattern of duration for the infiltrating capacity of imaginary units, catchment distribution of infiltrating capacity, surface runoff, and interflow, as well as soil evaporation and soil moisture prior to a rainfall event. The schematic diagram of the model is illustrated in Fig. 1.

\section{Steps of the Dynamic Critical Precipitation Method}

With respect to dynamic critical precipitation, functions are formulated for calculating dynamic critical precipitation under different soil moisture content, which are employed for early warning and forecasting of flash floods. The specific method and steps are given below:
1) The control section is selected based on the actual scenario, thereby deducing the relationship between water stage and discharge, and determining the flood discharge based on the flood stage. A disasterinducing flood stage is normally based on local stipulated flood prevention and control standard, or may be determined using the frequency analysis method.

2) Based on flood discharge, the net rainfall process required to generate a discharge of this magnitude is then deduced.

The time-history distribution process of net rainfall has a considerable influence on the flood peak. Based on analyses, it is accepted that under the identical condition of total effective precipitation, when the main rainfall occurs backward, a maximum peak flood discharge will emerge. Conversely, a minimal peak discharge will be generated. Namely, under the identical condition of peak flood discharge, the minimal total effective precipitation is required when the main rainfall occurs backward. Conversely, the maximal total effective precipitation will be required. 

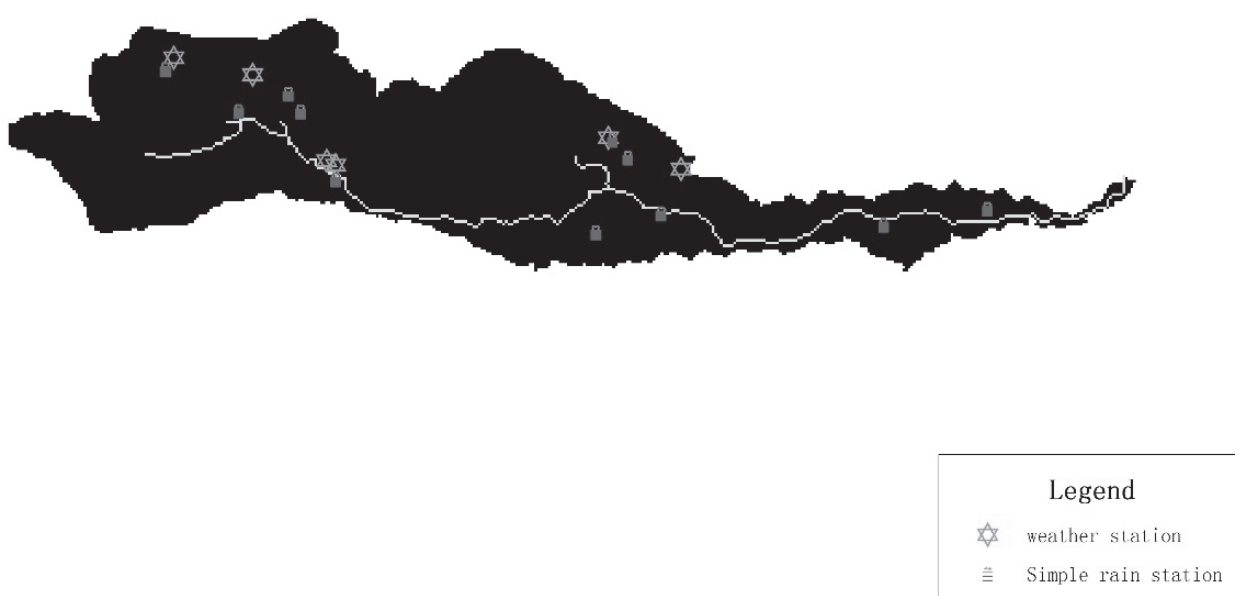

Fig. 2. Distribution of rain gauge stations and weather stations of Dayuhe Watershed.

Assume a series of net rainfall processes in which the main rainfall occurs either forward or backward with different durations, the unit hydrograph is adopted to calculate corresponding peak flood discharge. Thus, the net rainfall corresponding to the flood discharge will be the required net rainfall process. The details are presented as follows:

1) Adopt the intersection method to solve the mean effective precipitation intensity for duration $\tau$ : Assuming a set of mean net rainfall processes, based on composite instantaneous unit hydrograph method, a set of discharge hydrograph may be obtained; a set of peak flood discharges may be derived according to the time-interval concentration curve. Thus, curve $\mathrm{x}$ and $\mathrm{xx}$ are then plotted in the ordinary coordinate system, of which the horizontal coordinate of the intersection will be the mean rainfall intensity for duration $\tau$.

2) Using the calculated mean rainfall intensity for the duration $\tau$, calculate the flood hydrograph, thereby obtaining the corresponding peak flood discharge. If this peak discharge is identical to the flood discharge, then the corresponding net rainfall is what is desired.

3) Deduce critical precipitation for different durations using the inversion method based on the doubleexcess model.

- Calibrate the parameters of the double-excess model using a historical flood hydrograph.

- Based on the derived effective precipitation, assume a series of precipitation corresponding $H_{i}$ to different duration $t$ of main rainfalls.

- Input the assumed precipitation $H_{i}$ and the antecedent influencing precipitation into the double-excess model, thereby obtaining net rainfall depth for the flood. In the case that it equals the effective precipitation as calculated in the previous step, then the corresponding rainfall will be the critical precipitation of the catchment with associated percent saturation of soil moisture content and corresponding duration of the main rainfall.

\section{Results and Discussion}

\section{Overview of Dayuhe River Catchment}

The research catchment selected in this paper is Dayuhe River catchment, which is located in Huairen County, Shuozhou City. The Dayuhe River forms the primary tributary of the Sanggan River, which originates from Jiekou Mountain in Zuoyun county. Besides, its catchment covers an area of $239.17 \mathrm{~km}^{2}$ with a main channel of $42.25 \mathrm{~km}$ and a gradient of $18.6 \%$. Dayuhe catchment is mainly characterized by mountainous regions above Dayukou, and is mainly featured by plains below Dayukou. Besides, embankments are constructed along hazardous river segments above and close to Dayukou. The river, with a stable riverbed, flows from northwest toward the southeast within the catchment, and the landform mainly features sandstone, shale, scrubland, and grassy slope.

The period from June to September is the precipitation-concentration period (PCP) in summer for Dayuhe River catchment with a mean annual precipitation of $371.4 \mathrm{~mm}$. Besides, the maximum annual precipitation is $564.9 \mathrm{~mm}$ (1973), and minimum $190.4 \mathrm{~mm}$ (1965). The annual precipitation with nonuniform distribution mainly concentrates on the summer, which accounts for $77 \%$ of total annual precipitation.

\section{Catchment Subdivision}

In order to determine the areal weights for the calculation of areal rainfall in the catchment, according to the distribution of rain gauge stations in Dayuhe River catchment, linear interpolation is performed for the collected raw data, thereby precipitation and flood data for a duration of $1 \mathrm{~h}$ are derived. Taking into account the non-uniformity of rainfall distribution in the catchment, the Thiessen polygon weighted average method is adopted to calculate the mean areal rainfall for 4 gauge stations. The areal weight coefficient of rain gauge stations is presented in Table 1. 
Table 1. Weight allocation of rain gauge stations in Dayuhe River catchment.

\begin{tabular}{|c|c|c|c|}
\hline SN & Name of station & Weight & Area $\left(\mathrm{km}^{2}\right)$ \\
\hline 1 & Wanyao & 0.166 & 24.47 \\
\hline 2 & Yang Juan Tou & 0.1992 & 29.36 \\
\hline 3 & Liang Jia Dian & 0.1867 & 27.52 \\
\hline 4 & Si Shi Li Zhuang & 0.4481 & 66.05 \\
\hline
\end{tabular}

\section{Parameter Calibration of the Double-Excess Model}

The observed data on rainfall and runoff time intervals of Dayuhe River catchment for the period 1958-1989 are collected. 34 flood events that occurred during the period 1958-1989 are selected to construct the double-excess model. Besides, the calibration period is defined to the period 1958-1982 with a total of 24 flood events, and the test period is 1982-1989 with a total of 10 flood events. By means of the selected 24 flood events, SCE-UA global optimization algorithm is employed to identify optimal parameters. Flood simulation results based on the double-excess model are illustrated in Fig. 3.

\section{Operation Process}

\section{Principle for Identifying Early Warning Time Intervals}

1) According to factors that include characteristics of rainstorm and underlying surfaces for Shanxi Province, basic early warning time intervals are determined as $0.5 \mathrm{~h}, 1 \mathrm{~h}, 1.5 \mathrm{~h}, 2 \mathrm{~h}, 2.5 \mathrm{~h}, 3 \mathrm{~h}, 3.5 \mathrm{~h}$, $4 \mathrm{~h}, 4.5 \mathrm{~h}, 5 \mathrm{~h}, 5.5 \mathrm{~h}$, and $6 \mathrm{~h}$.

2) If the time for runoff concentration $\geq 6 \mathrm{~h}$, then early warning time intervals are identified as $1 \mathrm{~h}, 2 \mathrm{~h}, 3 \mathrm{~h}$, $6 \mathrm{~h}$, and runoff concentration time; if $<6 \mathrm{~h}$, then time intervals will be set to runoff concentration time and basic early warning time intervals that are less than the time of runoff concentration.

\section{Identification of Transfer Indicators}

1) Immediate transfer indictor: Due to the fact that critical precipitation is derived from the flood discharge corresponding to the disaster-inducing flood stage, therefore, critical precipitation is considered numerically to be the immediate transfer indictor.

2) Transfer preparation indicator: In the case of the early warning time interval of $0.5 \mathrm{~h}$, transfer preparation indicator $=$ immediate transfer indictor*0.7. In addition, when early warning time intervals are $0.5 \mathrm{~h}, 1 \mathrm{~h}, 1.5 \mathrm{~h}, 2 \mathrm{~h}, 2.5 \mathrm{~h}, 3 \mathrm{~h}$, and time of runoff concentration respectively, the immediate transfer indictor for first $0.5 \mathrm{~h}$ is equivalent to the transfer preparation indicator of this alert time interval.

\section{Design Rainfall Pattern}

When deducing early warning precipitation indicators using the inversion method based on the hydrological model, the time-history distribution of rainfall patterns will be involved, which will have a marked influence on the peak flood discharge. It is considered based on analyses that under the identical conditions of total effective precipitation, the maximal peak flood discharge will emerge when the main rainfall occurs backward. Conversely, a minimal peak discharge will be generated. Namely, under the identical condition of peak flood discharge, the minimal total effective precipitation is required when the main rainfall occurs backward. Conversely, the maximal total effective precipitation will be required. The design rainfall pattern corresponding to the subarea where Xiangning catchment is located in this study is sourced from the Hydrological handbook of Shanxi province.

\section{Proposed Functions for Calculating Dynamic Critical Precipitation}

Based on the analyses and calculation of runoff generation and concentration, the time of runoff

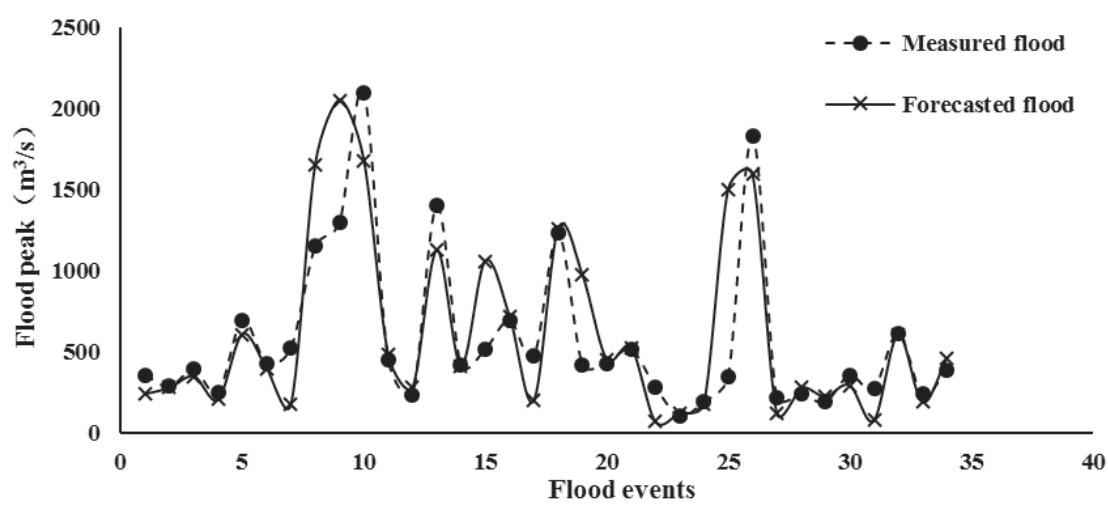

Fig. 3. Flood-fitting curve in double-excess model. 


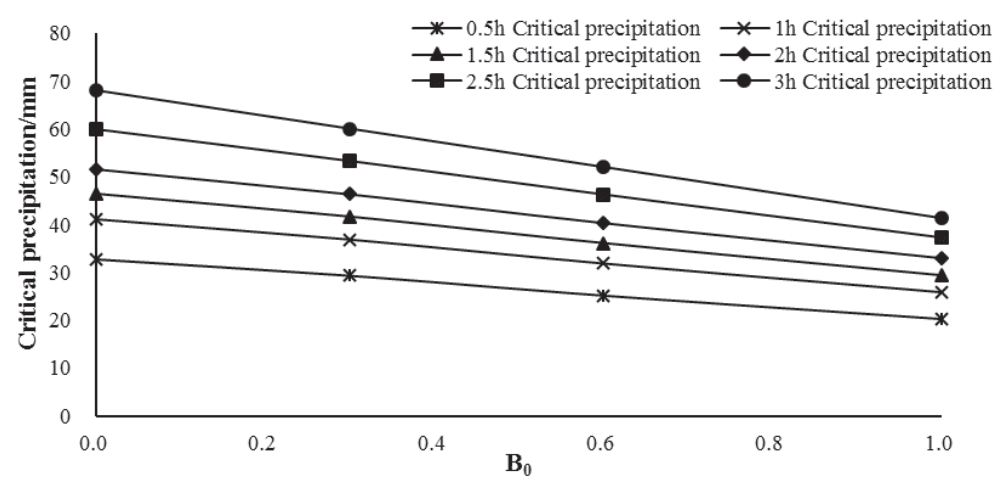

Fig. 4. Critical precipitation that triggers transfer preparations for Dayuhe catchment.

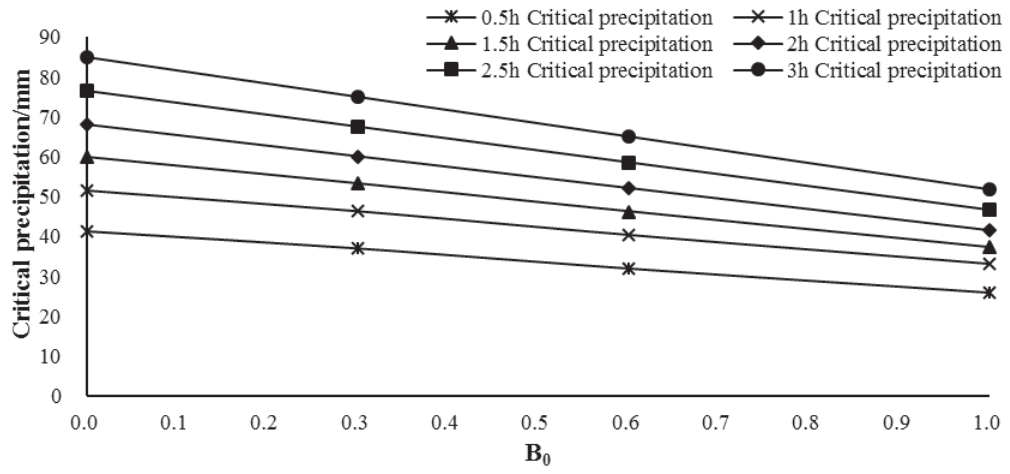

Fig. 5. Critical precipitation that triggers immediate transfer for Dayuhe catchment.

concentration derived for Dayuhe catchment is $2.6 \mathrm{~h}$. Therefore, cumulative precipitation for durations of $0.5 \mathrm{~h}, 1 \mathrm{~h}, 1.5 \mathrm{~h}, 2 \mathrm{~h}, 2.5 \mathrm{~h}$, and $3 \mathrm{~h}$, respectively, is selected for calculating critical precipitation indicators. Peak precipitation that triggers transfer preparations occurs 30 minutes earlier than that which triggers immediate transfer. For convenience and practicality, it is determined that the antecedent soil moisture $\mathrm{B}_{0}=0$ under arid conditions. Normally $\mathrm{B}_{0}=0.3$ and $\mathrm{B}_{0}=0.6$ under humid conditions.

Six time intervals of precipitation that trigger transfer preparations and immediate transfer for Dayuhe River catchment are derived from calculation, as illustrated above in Figs 4 and 5, which present a correlation diagram of dynamic critical precipitation trigging transfer preparations and immediate transfer, respectively. Besides, functions for computing dynamic critical precipitation under the conditions of different soil moisture content are established respectively.

Functions for computing critical precipitation that triggers immediate transfer:

$$
y=-0.4483 x^{2}-14.943 x+41.22
$$

$0.5 \mathrm{~h}$ cumulative critical precipitation relation

$$
y=-0.448 x^{2}-18.277 x+51.69
$$

$1 \mathrm{~h}$ cumulative critical precipitation relation

$$
y=-0.2246 x^{2}-22.471 x+59.89
$$

$1.5 \mathrm{~h}$ cumulative critical precipitation relation

$$
y=-0.0012 x^{2}-26.666 x+68.10
$$

$2 \mathrm{~h}$ cumulative critical precipitation relation

$$
y=-0.0001 x^{2}-30 x+76.57
$$

$2.5 \mathrm{~h}$ cumulative critical precipitation relation

$$
y=-0.0015 x^{2}-33.334 x+85.05
$$

$3 \mathrm{~h}$ cumulative critical precipitation relation

...where $x$ denotes the saturation level of soil moisture content andrepresents the computed indicator values of critical precipitation.

It may be concluded, based on the observations from early warning discriminant function for dynamic critical precipitation, that with the increase in the percentage saturation of soil moisture content, the critical precipitation that may induce a flash flood disaster decreases. With the increase in the time scale, the slope declines gradually, which shows that the greater the time scale, the greater the impact of percent saturation of soil moisture content on critical precipitation. Under the identical conditions of saturation level of soil moisture content, the greater the time scale, the greater the cumulative precipitation that may incur a disaster, 
which remains consistent with the pattern and actual regimes of runoff generation and concentration in the catchment.

\section{Conclusions}

In this paper, the flash flood early warning method based on dynamic critical precipitation is derived using the double-excess model and taking into account percentage saturation of soil moisture content. In this study, the dynamic critical precipitation method is based on the double-excess model and the unit hydrograph runoff concentration method. The simulation and analyses of runoff generation and concentration are carried out for the research catchment; discriminant functions for critical precipitation are deduced for various time scales and under different percentage saturations of soil moisture content. Moreover, historical flood hydrographs are adopted to validate the said results, which provide a reliable and visual basis for flash flood early warning.

1) Dynamic critical precipitation indicators are formulated taking into account the percentage saturation of soil moisture content, thereby overcoming the limitation of traditional static critical precipitation method that neglects soil moisture content, thus improving the accuracy of flash flood early warning indicators.

2) Using representative historical flood hydrograph data for the year xx of Hong An Jian He river catchment, six discriminant functions for flash flood dynamic critical precipitation indicators are derived for various time scales and under different percentage saturation of soil moisture content, which is applicable to Hong An Jian He river catchment.

3) The relationship between runoff generation and concentration is simulated using the double-excess model proposed in this paper. Therefore, it may be concluded that the shorter time of runoff generation and concentration for partial subdivided areas of the catchment in Shanxi province may be likely to induce flash flood disasters under intensive rainfall for short durations, which remains consistent with actual situations, and may be applied to flood early warning and forecasting in semi-arid and semi-humid areas similar to those of Shanxi Province.

\section{Acknowledgements}

This research was financially supported by urgency operation control and demonstration in the Middle Line of Water Diversion of South to North (2015BAB07B03). Language editing and improvement performed by Cactus Communications was also greatly appreciated.

\section{Conflict of Interest}

The authors declare no conflict of interest.

\section{References}

1. YE J., LI Z. The study and application of flash flood early warning methods based on dynamic critical precipitation. Journal of Meteorological Research, 1, 101, 2014.

2. REN C.F. The analytical study and application of flash flood early warning indicators for small watersheds in Shandong province. Shandong University, 1, 12015.

3. WANG X., TANG Y., ZHANG M, LEI C., GONG L. A study of critical precipitation for areas lacking hydrological data based on water stage/discharge inversion method. Journal of Water Resources and Water Engineering, 4, 125, 2016.

4. LIU Z., HOU A. WANG X. Flood forecasting techniques for medium and small rivers based on distributed hydrological model. Hydrology, 1, 1, 2015.

5. DU K., ZHAO Y., XIE J. A Study of Threshold Rainfall for Mountain Flood Forecast in Nana River, Taohe basin. China Flood \& Drought Management, 1, 23, 2013.

6. ZHANG L., WANG W., WEN M.Z. Research on Refined Early-Warning Method of Mountain Flood Disaster Based on FloodArea. Journal of Fudan University, 1, 1, 2015.

7. SHAMIR E., GEORGAKAKOS K.P., SPENCER C. Evaluation of real-time flash flood forecasts for Haiti during the passage of Hurricane Tomas, November 4-6. Natural Hazards, 67 (2), 459, 2013.

8. GE H. Parameters of Double Infiltration Model Calibratio Based on SCE - UA. Water Conservancy Science and Technology and Economy, 22 (7), 26, 2016.

9. QIU L., XUE F. The application of double-excess model in flood forecasting in a small watershed. Henan Hydraulics and South-North Water Transfer, 1, 1, 2017.

10. SUN W., WANG P., HE F., ZHANG Y., LIANG G.Comparative Study of Flood Simulation Methods at Small Watershed, Journal of Water Resources Research, $\mathbf{5}$ (3), 6, 2016.

11. ZHANG J., ZHANG W. AND XING B. The application of SCE - UA methods in the optimization of hydroenvironmental system. Water Resources Protection, 3, 61, 2014.

12. CHENG W. A review of rainfall thresholds for triggering flash floods. Advances in Water Science, 6 (24), 901, 2013.

13. LI C., WANG H., CHENG X., YUAN B., MA M., LIU C., SUN D. Critical Rainfall Analysis on Flash Flood Early Warning for South Branch of Censhui Watershed. Journal of Hydraulic Engineering, 1, 1, 2016.

14. WANG Y., WANG Y. Discussion on unsaturated soil of Richards infiltration equation. Hydrogeology and Engineering Geology, 31 (1), 9, 2004.

15. LI L., YAN Y., SHEN B. The application of double-excess model in semi-humid areas. Journal of North University of China (Natural science), 1, 62, 2008.

16. CAO Y., SUN X. Applicationand Improvement of Shuangchao Model in Zhangfeng Reservoir. Yellow River, 38 (11), 58, 2016. 
